\title{
Gene expression of growth factor BMP15, GDF9, FGF2 and their receptors in bovine follicular cells
}

\section{Expresión génica del factor de crecimiento BMP15, GDF9, FGF2 y sus receptores en células foliculares bovinas}

\author{
Pablo S. Reineri1,2 M.Sc, María S. Coria2,3 Lic, María G. Barrionuevo 2,3 Ph.D, \\ Olegario Hernández ${ }^{1}$ M.Sc, Santiago Callejas ${ }^{4}$ Ph.D, Gustavo A. Palma²,3* Ph.D.
}

\begin{abstract}
${ }^{1}$ National Institute of Agricultural Technology, EEA Santiago del Estero, Santiago del Estero, Argentina. ${ }^{2}$ National University of Santiago del Estero (UNSE), Santiago del Estero, Argentina. ${ }^{3}$ Animal Production Laboratory, INBIONATEC, Villa El Zanjón, Santiago del Estero, Argentina. ${ }^{4}$ Reproduction Area, FISFARVET, CIVETAN, CONICET-CICPBA, National University of the Center of the Province of Buenos Aires (UNICEN), Tandil, Argentina.*Correspondence: gustavo.palma@reprobiotec.com
\end{abstract}

Received: February 2018; Accepted: July 2018.

\begin{abstract}
Objective. Evaluate mRNA expression of GDF9, BMP15, FGF2 and their main receptors, transforming growth factor beta receptor 1 (TGFB-R1), bone morphogenetic protein receptor, type IB (BMPR-IB) and fibroblast growth factor receptor 2 (FGFR2) in bovine follicular cells. Materials and methods. Total RNA was isolated from pooled samples of oocytes (OOs), cumulus cells (CCs) of cumulus oocyte complexes (COCs) and follicular cell pellets (PCs) of 70 ovaries obtained from 96 beef heifers, collected at a local abattoir. The expression pattern of growth factors and their receptors in follicular bovine cells was evaluated by reverse transcriptase polymerase chain reaction (RT-PCR). Results. The mRNA transcripts encoding GDF9, BMP15, FGF2, TGFB-R1, BMPR-IB and FGFR2 genes were detected, by RT-PCR, in all studied cells. This is the first time that the expression of TGF $\beta-R 1$ and $B M P R-I B$ receptors is reported in bovine oocytes. Conclusions. The presence of growth factors and receptor transcripts in the studied cells indicate that these factors could act as paracrine and autocrine regulators of folliculogenesis.
\end{abstract}

Keywords: Oocyte; granulosa cells; growth factors; PCR; bovine (Source: AGROVOC).

\section{RESUMEN}

Objetivo. Evaluar la expresión de los factores de crecimiento GDF9, BMP15, FGF2 y sus principales receptores: el receptor 1 del factor de crecimiento transformante beta (TGF $\beta-R 1)$, el receptor de la proteína morfogénica del hueso tipo IB $(B M P R-I B)$ y el receptor del factor de crecimiento fibroblástico 2 (FGFR2) en células foliculares bovinas. Materiales y métodos. Se realizó la extracción de ARN total de pooles de ovocitos (OOs) y células del cumulus (CCs) de complejos cumulus-ovocito (COCs) y del pellet de células foliculares (PCs) provenientes de 70 ovarios obtenidos de 96 vaquillonas para carne, colectados en un frigorífico local. Los patrones de expresión de los factores de crecimiento y sus receptores en las células foliculares bovinas fueron evaluados por retro-transcripción seguida de la reacción en cadena de la polimerasa (RT-PCR). Resultados. La presencia de los transcriptos de ARNm de los genes GDF9, BMP15, FGF2, TGF $\beta-R 1, B M P R-I B$ y FGFR2 fue detectada por RT-PCR en todas las células estudiadas. Es la primera vez que se reporta en ovocitos bovinos la expresión de los receptores TGF $\beta-R 1$ y BMPR-IB. Conclusiones. La presencia de transcriptos de factores de crecimiento y sus receptores en las células estudiadas, indica que estos factores podrían actuar como reguladores paracrinos y autocrinos de la foliculogénesis.

Palabras claves: Ovocitos; células de la granulosa; factores de crecimiento; PCR; bovinos (Fuente: AGROVOC). 


\section{INTRODUCTION}

The potential of an oocyte to develop into a viable embryo depends on the accumulation of mRNA or imprinted genes during the process of oogenesis. Thus there is a general agreement that the development competence of oocyte could be related to an abundance of a specific RNA transcript pool that is accumulated during oocyte growth and at final phases of folliculogenesis (1) , favoring fertilization, implantation and generate healthy offspring. To clarify the importance of the contribution of the oocyte to the embryo quality, it is important to define more precisely the different types of competence expressed by oocytes. The ability to resume meiosis, to cleave upon fertilization to develop into a blastocyst, to induce pregnancy and to generate an healthy offspring are all separate events and succeeding in the first events does not ensure the success of subsequent ones. Furthermore, these events are associated with the three types of maturation processes observed in the oocyte: meiotic, cytoplasmic and molecular. These abilities vary also upon the type of follicle the oocytes is removed from. Larger or slow-growing follicles have been shown to foster better eggs than small or actively growing follicles. Hormonal stimulation can also affect oocyte competence with the nature of the effect (positive or negative). Folliculogenesis and follicle differentiation are processes that culminate in ovulation, being mainly coordinated by well-established endocrine mechanisms. This processes are the result of cellular and molecular transformations of the different structures that form the follicle (2).

Members of the transforming growth factor beta (TGF $\beta$ ) super family and the heparin union growth factor family, are known to be important regulators of proliferation and differentiation of several types of cells (3). The growth differentiation factor 9 (GDF9), the bone morphogenetic protein 15 (BMP15), members of the family of growth transforming factor $\beta$ (TGF $\beta$ ), and the basic fibroblast growth factor (FGF2), member of the family of heparin union growth factors with their main receptors, have been involved in dominant follicle selection, regulating important events such as proliferation of granulosa cells, differentiation and steroidogenesis $(4,5)$. GDF9 and BMP15 generate signals through their specific receptors, ie, transforming growth factor, beta receptor 1 , (TGF $\beta-R 1$ or ALK5) and bone morphogenetic protein receptor, type IB, (BMPR-IB or ALK6), respectively, whereas FGF2 factor binds primarily to fibroblast growth factor receptor 2 (FGFR2) $(6,7)$.

\section{INTRODUCCIÓN}

El potencial de un ovocito para convertirse en un embrión viable depende de la acumulación de ARNm o genes impresos durante el proceso de oogénesis. Por lo tanto, existe un acuerdo general de que la competencia de desarrollo de ovocito podría estar relacionada con una abundancia de un grupo de transcripción de ARN específico que se acumula durante el crecimiento de oocitos y en fases finales de foliculogénesis (1), favoreciendo la fertilización, implantación y generación de descendencia sana. Para aclarar la importancia de la contribución del ovocito a la calidad del embrión, es importante definir con mayor precisión los diferentes tipos de competencia expresados por los ovocitos. La capacidad de reanudar la meiosis, de adherirse a la fecundación para convertirse en un blastocisto, de inducir la preñez y de generar una descendencia sana, son todos eventos separados y el éxito en los primeros eventos no garantiza el éxito de los posteriores. Además, estos eventos están asociados con los tres tipos de procesos de maduración observados en el ovocito: meiótico, citoplásmico y molecular. Estas habilidades también varían según el tipo de folículo del que se extraen los ovocitos. Se ha demostrado que los folículos más grandes o de crecimiento lento fomentan mejores óvulos que los folículos pequeños o en crecimiento activo. La estimulación hormonal también puede afectar la competencia de los ovocitos con la naturaleza del efecto (positivo o negativo). La foliculogénesis y la diferenciación de los folículos son procesos que culminan en la ovulación, estando principalmente coordinados por mecanismos endocrinos bien establecidos. Estos procesos son el resultado de transformaciones celulares y moleculares de las diferentes estructuras que forman el folículo (2).

Los miembros de la superfamilia del factor de crecimiento transformante beta (TGFß) y de la familia del factor de crecimiento de la unión de la heparina son conocidos por ser importantes reguladores de la proliferación y diferenciación de varios tipos de células (3). El factor de diferenciación del crecimiento 9 (GDF9), la proteína morfogenética ósea 15 (BMP15), miembros de la familia del factor transformador del crecimiento $\beta$ (TGF $\beta$ ) y el factor de crecimiento básico de los fibroblastos (FGF2), miembro de la familia de los factores de crecimiento de la unión de la heparina con sus principales receptores, han estado involucrados en la selección del folículo dominante, regulando eventos importantes como la proliferación, diferenciación de las células de la granulosa y la esteroideogénesis $(4,5)$. El GDF9 y el BMP15 generan señales a través de sus receptores específicos, es decir, el factor de crecimiento transformante, el receptor beta 1, (TGF $\beta-R 1$ o ALK5) y el receptor de proteína morfogenética ósea, tipo IB, (BMPR-IB o ALK6), respectivamente, mientras que el factor FGF2 se une principalmente al receptor del factor de crecimiento de los fibroblastos 2 (FGFR2) $(6,7)$. 
The expression of GDF9, BMP15 and FGF2 have been reported in rodents, sheep's, buffalo and humans in oocyte, cumulus cells and ganulosa cells $(4,5,8)$ and there is convincing evidence that they are important for ovarian function. However, there is little information about the expression of these factors in cows. Since cattle have been used for many purposes they are highly attractive livestock animals from an economic point of view. Therefore, it is desirable to improve the knowledge about their reproductive physiology, especially the control of ovarian folliculogenesis. In order to explore the intracellular modulatory system of GDF9, BMP15 and FGF2 in bovine ovaries, the goal of present study was to evaluate mRNA expression of GDF9, BMP15, $F G F 2$ and their main receptors, TGF $\beta-R 1, B M P R-$ $I B$ and FGFR2, by using reverse transcriptase polymerase chain reaction (RT-PCR).

\section{MATERIALS AND METHODS}

Animals and follicular cells. Protocols used on animal were applied according to the standards and care described in the Official Journal of the European Union (9). Healthy bovine ovaries with normal morphology and no corpus luteum were collected from 70 ovaries obtained from 96 slaughtered beef heifers, during NovemberDecember 2015 and January-July 2016. The ovaries were placed into PBS solution at $37^{\circ} \mathrm{C}$ and delivered to the laboratory within 2 hours of collection. The cumulus-oocyte complexes (COCs) were recovered by manual aspiration of antral follicles ( $\leq 6 \mathrm{~mm}$ diameter) using $10 \mathrm{ml}$ syringes with $40 \times 1.2 \mathrm{~mm}(18 \mathrm{G})$ needles, and pooled in a sterile $50 \mathrm{~mL}$ conical bottom centrifuge tube with PBS. The tubes were kept at $37^{\circ} \mathrm{C}$ for 15 min for the settlement of COCs. The sediment was mixed with PBS and screened for COCs under a stereozoom microscope. The aspirated COCs were graded based on the morphological appearance of the cumulus cell investments and homogeneity of ooplasm as described by de Loos et al (10). Pools of 30 COCs qualitatively good (Grade 1 and Grade 2) were separated from the cumulus cells by repeated pipetting and then were recovered. Subsequently, three pools of 30 oocytes and three pools of cumulus cells, which were separated from the 30 oocytes, were made.

The follicular liquid, was centrifuged at 12.000 $\mathrm{x} \mathrm{g}$ for $10 \mathrm{~min}$ at $4^{\circ} \mathrm{C}$, obtaining three pellet of cells composed by granulosa cells and theca cells (PCs). All samples were snap-frozen in liquid Nitrogen and stored at $-70^{\circ} \mathrm{C}$ until their analysis.

Extraction and purification of total RNA on follicular cells and oocytes. Total RNA was extracted from samples of follicular cells
La expresión de GDF9, BMP15 y FGF2 ha sido reportada en roedores, ovejas, búfalos y humanos en ovocitos, células del cumulus y de la granulosa $(4,5,8)$ y existe evidencia convincente de que son importantes para la función ovárica. Sin embargo, hay poca información sobre la expresión de estos factores en el ganado vacuno. Dado que el ganado vacuno se ha utilizado para muchos fines, es un animal muy atractivo desde el punto de vista económico. Por lo tanto, es deseable mejorar el conocimiento sobre su fisiología reproductiva, especialmente el control de la foliculogénesis ovárica. Para explorar el sistema modulador intracelular de GDF9, BMP15 y FGF2 en ovarios bovinos, el objetivo del presente estudio fue evaluar la expresión de ARNm de GDF9, BMP15, FGF2 y sus principales receptores, TGFB-R1, BMPR-IB y FGFR2, utilizando la transcripción reversa seguida de la reacción en cadena de la polimerasa (RT-PCR).

\section{MATERIALES Y MÉTODOS}

Animales y células foliculares. Los protocolos utilizados con los animales se aplicaron de acuerdo con las normas y los cuidados descritos en el Diario Oficial de la Unión Europea (9). Se recolectaron ovarios bovinos sanos con morfología normal y sin cuerpo lúteo de 70 ovarios obtenidos de 96 vaquillonas para carne sacrificadas, durante los meses de noviembrediciembre de 2015 y enero-julio de 2016. Los ovarios se colocaron en una solución de PBS a $37^{\circ} \mathrm{C}$ y fueron trasladadas al laboratorio dentro de las 2 horas de la recolección. Los complejos cúmulo ovocitos (COCs) se recuperaron mediante aspiración manual de folículos antrales $(\leq 6 \mathrm{~mm}$ de diámetro) utilizando jeringas de $10 \mathrm{ml}$ con agujas de $40 \times 1.2 \mathrm{~mm}$ (18 G), y se colocaron en un tubo de centrífuga estéril de fondo cónico de $50 \mathrm{~mL}$ con PBS. Los tubos se mantuvieron a $37^{\circ} \mathrm{C}$ durante 15 minutos para la sedimentación de los COCs. El sedimento se mezcló con PBS y se examinó para detectar COCs bajo un microscopio estereoscópico. La clasificación de los COCs aspirados se basó en la apariencia morfológica de las inversiones de los cúmulos celulares y la homogeneidad del ooplasma, según lo descrito por de Loos et al (10). Los grupos de 30 COCs cualitativamente buenos (Grado 1 y Grado 2) se separaron de las células del cúmulo mediante pipeteo repetido y luego se recuperaron. Posteriormente, se formaron tres grupos de 30 ovocitos y tres grupos de cúmulos celulares, obtenidos de los 30 ovocitos.

El líquido folicular, se centrifugó a 12.000 $x$ g durante $10 \mathrm{~min}$ a $4^{\circ} \mathrm{C}$, obteniendo tres sedimentos de células compuestas por células granulosas y células de la teca (PCs). Todas las muestras se congelaron rápidamente en nitrógeno líquido y se almacenaron $\mathrm{a}-70^{\circ} \mathrm{C}$ hasta su análisis. 
following the Phenol-Chloroform method using TriReagent ${ }^{\circledR}$ (Sigma) according to manufacturer instructions. Briefly, samples were homogenized with $250 \mu \mathrm{l}$ TriReagent ${ }^{\circledR}$, then $50 \mu \mathrm{l}$ chloroform was added and merged for $15 \mathrm{sec}$ followed by centrifugation at $12.000 \times \mathrm{g}$ for $15 \mathrm{~min}$ at $4^{\circ} \mathrm{C}$. The upper aqueous phase, containing RNA, was transferred to a new tube and isopropanol was added. Samples were kept at room temperature for $10 \mathrm{~min}$ and centrifuged at $12.000 \times \mathrm{g}$ for $10 \mathrm{~min}$ at $4{ }^{\circ} \mathrm{C}$. Supernatant was removed and RNA pellet was washed with ethanol $75 \%$ and centrifuged at $7.500 \times \mathrm{g}$ for $5 \mathrm{~min}$ at $4^{\circ} \mathrm{C}$. Total RNA samples were suspended on ribonucleasesfree $\mathrm{H}_{2} \mathrm{O}$ and concentration and integrity of RNA were assessed by absorbance at $260 \mathrm{~nm}$ utilizing NanoDrop 2000c UV-Vis Spectrophotometer (Thermo Scientific, U.S.A), and electrophoresis on Sybr Green stained agarose gels (Biotium). Prior to CDNA synthesis, DNase (AMPD1- Sigma) treatment was applied. Reverse transcription was performed using SuperScript III Reverse Transcriptase (Invitrogen). Every $20 \mu \mathrm{L}$ of reaction contained $1 \mu$ l of Oligo dT $(50 \mu \mathrm{M}), 1 \mu \mathrm{l}$ of dNTPs, $4 \mu \mathrm{l}$ of $5 X$ First Strand Buffer, $1 \mu \mathrm{l}$ of 0.1 M DTT, 40 units of RNAsin (Genbiotech), 200 units of SuperScriptIII reverse transcriptase, a volume of RNA (1.200 ng), and nuclease-free water to complete the final volume. The mixture was held $1 \mathrm{~h}$ at $50^{\circ} \mathrm{C}$ and $15 \mathrm{~min}$ at $70^{\circ} \mathrm{C}$ prior to cooling on ice. Finally, samples were stored at $-70^{\circ} \mathrm{C}$ till their subsequent analysis.

Primer design. Taking into account the sequences recently published by the National Center for Biotechnology Information (NCBI) and the data base of the bovine genome sequence, specific primers were designed in order to amplify bovine gene coding regions GDF9, BMP15, FGF2, TGFB-R1, BMPR-IB and FGFR2 using the online software PrimerBLAST and Integrated DNA Technologies (IDT) (Table 1). Additionally, the quality and purity of samples used was determined with specific primers GAPDH (glyceraldehyde-3-phosphate dehydrogenase), for oocyte (ZAR1: zygote arrest-1), granulosa cells (CYP19A1: cytochrome P450, family 19 , subfamily A, polypeptide 1 ) and theca cells (CYP17A1: cytochrome P450, family 17 , subfamily $A$, polypeptide 1 ) as suggested Hatzirodos et al (11) (Table 1).

Amplificaction by PCR. PCR reactions were performed by triplicate using CDNA of both follicular cells and oocytes. For this, mixtures containing $10 \mu \mathrm{M}$ of each primer, $0.2 \mathrm{mM}$ of each dNTP, 1 unit of Taq DNA polimerase (Genbiotech) and buffer solution of $10 \mathrm{X}$ reaction (Tris- $\mathrm{HCl} 10$ $\mathrm{mM}$; KCl 50 mM; Triton X-100 0.1\%; $\mathrm{MgCl}_{2} 2$ mM,
Extracción y purificación del ARN total en células foliculares y ovocitos. EI ARN total se extrajo de muestras de células foliculares siguiendo el método de Fenol-Cloroformo utilizando TriReagent ${ }^{\circledR}$ (Sigma) de acuerdo con las instrucciones del fabricante. Brevemente, las muestras se homogeneizaron con $250 \mu \mathrm{l}$ de TriReagent ${ }^{\circledR}$, luego se añadieron $50 \mu \mathrm{l}$ de cloroformo y se mezclaron durante 15 segundos, seguido de una centrifugación a $12.000 \times \mathrm{g}$ durante 15 minutos a $4^{\circ} \mathrm{C}$. La fase acuosa superior, que contiene ARN, se transfirió a un nuevo tubo y se añadió isopropanol. Las muestras se mantuvieron a temperatura ambiente durante 10 minutos y se centrifugaron a $12.000 \mathrm{x}$ g durante 10 minutos a $4{ }^{\circ} \mathrm{C}$. Se eliminó el sobrenadante y el sedimento de ARN se lavó con etanol al $75 \%$ y se centrifugó a $7.500 \times$ g durante 5 minutos a $4{ }^{\circ} \mathrm{C}$. Las muestras de ARN total fueron suspendidas en $\mathrm{H} 2 \mathrm{O}$ libre de ribonucleasas y la concentración e integridad de ARN fueron evaluadas por absorbancia a $260 \mathrm{~nm}$ utilizando el espectrofotómetro NanoDrop 2000c UV-Vis (Thermo Scientific, EE.UU.), y electroforesis en geles de agarosa teñidos Sybr Green (Biotium). Antes de la síntesis de ADN complementario (ADNC), se realizó un tratamiento con DNasa (AMPD1- Sigma). La transcripción inversa se realizó utilizando SuperScript III Reverse Transcriptase (Invitrogen). Cada $20 \mu \mathrm{L}$ de reacción se agregaron $1 \mu \mathrm{l}$ de Oligo dT $(50 \mu \mathrm{M})$, $1 \mu \mathrm{l}$ de dNTPs, $4 \mu \mathrm{l}$ de $5 X$ First Strand Buffer, $1 \mu \mathrm{l}$ de $0.1 \mathrm{M}$ DTT, 40 unidades de RNAsin (Genbiotech), 200 unidades de transcriptasa reversa, un volumen de RNA (1.200 ng), y agua libre de nucleasasas para completar el volumen final. La mezcla se mantuvo $1 \mathrm{~h}$ a $50^{\circ} \mathrm{C}$ y $15 \mathrm{~min}$ a $70^{\circ} \mathrm{C}$ antes de enfriarla en hielo. Finalmente, las muestras se almacenaron a $-70^{\circ} \mathrm{C}$ hasta su posterior análisis.

Diseño de cebadores. Teniendo en cuenta las secuencias recientemente publicadas por el Centro Nacional de Información Biotecnológica (NCBI) y la base de datos de la secuencia del genoma bovino, se diseñaron cebadores específicos para amplificar las regiones codificadoras de genes bovinos GDF9, BMP15, FGF2, TGFB-R1, BMPR-IB y FGFR2 utilizando el software en línea Primer-BLAST y Integrated DNA Technologies (IDT) (Tabla 1). Además, se determinó la calidad y pureza de las muestras utilizadas, con cebadores específicos GAPDH (gliceraldehído-3-fosfato deshidrogenasa), para ovocitos (ZAR1: detención de cigoto-1), células granulosas (CYP19A1: citocromo P450, familia 19 , subfamilia $A$, polipéptido 1 ) y células teca (CYP17A1: citocromo P450, familia 17, subfamilia A, polipéptido 1 ), como se sugirió en el estudio de Hatzirodos (11) (Tabla 1). 
Table 1. Oligonucleotide sequences used for reverse transcriptase PCR assays (RT-PCR)

\begin{tabular}{|c|c|}
\hline Assay name ${ }^{1}$ & Primers ${ }^{2}$ \\
\hline \multirow[t]{3}{*}{ GDF9 } & F: TGCACCTGTCTATGCCTTTG \\
\hline & R: AACATTTGGCCATGAGGAAG \\
\hline & A: 157; AN: XM_010807219.1 \\
\hline \multirow[t]{3}{*}{ BMP15 } & F: TCAGGAAGAGGCTCCTCAAA \\
\hline & R: CCACCAGAACTCACGAACCT \\
\hline & A: 168; AN: NM_001031752.1 \\
\hline \multirow[t]{3}{*}{ FGF2 } & F: AAGCGGCTGTACTGCAAGAA \\
\hline & R: GTAGTTTGATGTGTGGGTCGC \\
\hline & A: $100 ;$ AN: NM_174056.4 \\
\hline \multirow[t]{3}{*}{$T G F \beta-R 1$} & F: GATTCGGCCACGGATACAA \\
\hline & R: GTCGAGCTACTTCCCAGAATAC \\
\hline & A: $110 ;$ AN: NM_174621.2 \\
\hline \multirow[t]{3}{*}{$B M P R-I B$} & F: TाTGGGAGGTCGCTAGGAGA \\
\hline & R: GCCGCAGCTTCTTGATACAC \\
\hline & A: 132; AN: XM_005207720.2 \\
\hline \multirow[t]{3}{*}{ FGFR2 } & F: ATGTCGCTTATCGAGCCACC \\
\hline & R: GCGTGGCACCTTTTATCTGC \\
\hline & A: 199; AN: XM_010820098.2 \\
\hline \multirow[t]{3}{*}{ GAPDH } & F:AGATGGTGAAGGTCGGAGTG \\
\hline & R:GAAGGTCAATGAAGGTCA \\
\hline & A:117; AN: NM_001034034 \\
\hline \multirow[t]{3}{*}{ CYP19A1 } & F: GTGTCCGAAGTTGTGCCTATT \\
\hline & R: GGAACCTGCAGTGGGAAATGA \\
\hline & A: 148; AN: NM_174305.1 \\
\hline \multirow[t]{3}{*}{ CYP17A1 } & F: ACCATCAGAGAAGTGCTCCGAA \\
\hline & R: CCACAACGTCTGTGCCTTTGT \\
\hline & A: $115 ;$ AN: NM_174304.2 \\
\hline \multirow[t]{3}{*}{ ZAR1 } & F: TGCCGAACATGCCAGAAG \\
\hline & R: TCACAGGATAGGCGTTTGC \\
\hline & A: 169; AN: NM_001076203 \\
\hline
\end{tabular}

${ }^{1}$ Abbreviated mRNA transcript identifiers for GDF9: Growth differentiation factor, BMP15: Bone morphogenetic protein 15, FGF2: Fibroblast growth factor 2, TGF $\beta-R 1$ : Transforming growth factor, beta receptor 1 , BMPR-IB: Bone morphogenetic protein receptor, type 1B, FGFR2: Fibroblast growth factor receptor 2, CYP19A1: cytochrome P450, family 19, subfamily A, polypeptide 1, CYP17A1: cytochrome P450, family 17, ZAR1: zygote arrest-1

2 Details of specific primers sets used: $F$ : forward primer sequence ( 5 ' to $\left.3^{\prime}\right), R$ : reverse primer sequence $\left(5^{\prime}\right.$ to $\left.3^{\prime}\right), A$ : Amplicon length in base pairs and AN: Accession Number.

$\mathrm{pH}: 9.0)$ in a $20 \mu \mathrm{l}$ final volume. The amplification program used consisted of a denaturation step at $94^{\circ} \mathrm{C}$ for 5 min followed by 40 amplification cycles consisting of a denaturation step at $94^{\circ} \mathrm{C}$ for 20 $\mathrm{sec}$, hybridization at $58^{\circ} \mathrm{C}$ for $30 \mathrm{sec}$, extension at $72^{\circ} \mathrm{C}$ for $1 \mathrm{~min}$ and finally a period of $7 \mathrm{~min}$ at $72^{\circ} \mathrm{C}$. No-template and no-reverse transcription controls were included as negative controls and to exclude genomic DNA contamination. Specificity of PCR products was confirmed by electrophoresis on agarose gel and sequencing.
Amplificación por PCR. Las reacciones de PCR se realizaron por triplicado utilizando ADNc tanto de células foliculares como de ovocitos. Para ello, mezclas que contengan $10 \mu \mathrm{M}$ de cada cebador, $0.2 \mathrm{mM}$ de cada dNTP, 1 unidad de Taq DNA polimerasa (Genbiotech) y el buffer de la enzima $10 \mathrm{X}$ (Tris- $\mathrm{HCl} 10 \mathrm{mM} ; \mathrm{KCl} 50$ $\mathrm{mM}$; Triton X-100 0.1\%; $\left.\mathrm{MgCl}_{2} 2 \mathrm{mM}, \mathrm{pH}: 9,0\right)$ en un volumen final de $20 \mu \mathrm{l}$. El programa de amplificación utilizado consistió en un paso de desnaturalización a $94^{\circ} \mathrm{C}$ durante 5 min, seguido de 40 ciclos de amplificación que consistieron en un paso de desnaturalización a $94^{\circ} \mathrm{C}$ durante 20 seg, hibridación a $58^{\circ} \mathrm{C}$ durante $30 \mathrm{seg}$, extensión a $72^{\circ} \mathrm{C}$ durante $1 \mathrm{~min}$. y finalmente un período de 7 min a $72^{\circ} \mathrm{C}$. Se incluyeron como controles negativos y para excluir la contaminacion con ADN genomico, reacciones sin ADNc y sin RT. La especificidad de los productos de PCR fue confirmada por electroforesis en gel de agarosa y secuenciación.

\section{RESULTADOS}

Mediante el uso de RT-PCR demostramos la presencia de ARNm de GDF9, BMP15, FGF2, TGF $\beta-R 1, B M P R-I B$ y FGFR2 en cúmulos, pellets de células foliculares (granulosa y células teca) de folículos antrales ( $\leq 6 \mathrm{~mm}$ diameter), así como en ovocitos. Para todos los ARNm estudiados pudimos obtener un solo amplicón del tamaño esperado (Figura 1).

Para descartar una posible contaminación cruzada cuando cada tipo de célula fue aislada, se realizó RTPCR utilizando cebadores específicos. La expresión de ARNm del gen CYP19A1, específico para células de granulosa, sólo se detectó en cúmulos y pellets de células foliculares; el gen CYP17A1, específico para células teca, sólo se detectó en pellets de células foliculares. Por último, los transcritos ZAR1, específicos para los ovocitos, se detectaron sólo en las muestras de ADNc de los ovocitos, pero no en muestras de ADNc de las células cúmulos, y en los gránulos de células foliculares.

\section{DISCUSIÓN}

El factor de diferenciación del crecimiento 9 desempeña múltiples funciones en el ovocito y las células de la granulosa, favoreciendo la comunicación, regulación y diferenciación celular (4). Se ha sugerido que el GDF9 podría influir en la maduración folicular y la ovulación en humanos estimulando la síntesis de inhibinas (12). El gen BMP15 también juega un papel crítico en la función ovárica, estimulando la proliferación de células preantrales de granulosa e inhibiendo la producción de progesterona estimulada por la FSH en células de granulosa en estadio avanzado(4). 


\section{RESULTS}

By using RT-PCR we demonstrated the presence of mRNA of GDF9, BMP15, FGF2, TGF $\beta-R 1$, $B M P R-I B$ and FGFR2 on cumulus, follicular cell pellet (granulosa and theca cells) from antral follicles ( $\leq 6 \mathrm{~mm}$ diameter), as well as in oocytes. For all of mRNA studied we were able to obtain a single amplicon of expected size (Figure 1).

In order to discard a possible cross contamination when each kind of cell was isolated, RT-PCR using specific primers was conducted. The mRNA expression of the CYP19A1 gene, specific for granulosa cells, only was detected in cumulus and follicular cell pellet; CYP17A1 gene, specific for theca cells, was detected only in follicular cell pellet. Finally, ZAR1 transcripts, specific for oocyte, were detected only in the cDNA template of the oocytes, but not in the cDNA template of cumulus cells, and follicular cell pellet.

\section{DISCUSSION}

Growth differentiation factor 9 plays multiple functions in oocyte and granulosa cell communication, regulation and differentiation (4). It has been suggested that GDF9 could influence follicular maturation and ovulation in humans by stimulating inhibin synthesis (12). The BMP15 gene also plays a critical role in ovarian function stimulating the proliferation of pre-antral granulosa cells and inhibiting $\mathrm{FSH}-$ stimulated progesterone production in later stage granulosa cells (4).

When comparing rodents with an incomplete estrous cycle (mice, rats) to animals with a complete estrous cycle (humans, goats, pigs and cows), GDF9 and BMP15 appear in different tissues. The mRNA expression of the transforming growth factors-beta studied was detected exclusively in oocytes of rodents (13), while in other species, including humans (14), goats (15), sheep $(8,16)$, pigs (17) and cows $(18,19), B M P 15$ and GDF9 were expressed in cumulus cells as well as in oocytes, in agreement with the result obtained in this work. Additionally, in the present study, BMP15 and GDF9 were also expressed in the pellet of cells, where granulosa and theca cells were expresed. These results could be explained by species specific differences in the mechanisms of action of key biological functions among the different follicle cells. In agreement with other authors, these differences could be explained by differences on physiological and reproductive forms of the studied species, suggesting that these factors regulate the ovulation rate and female fertility in a species-specific manner $(20,21)$. Recently

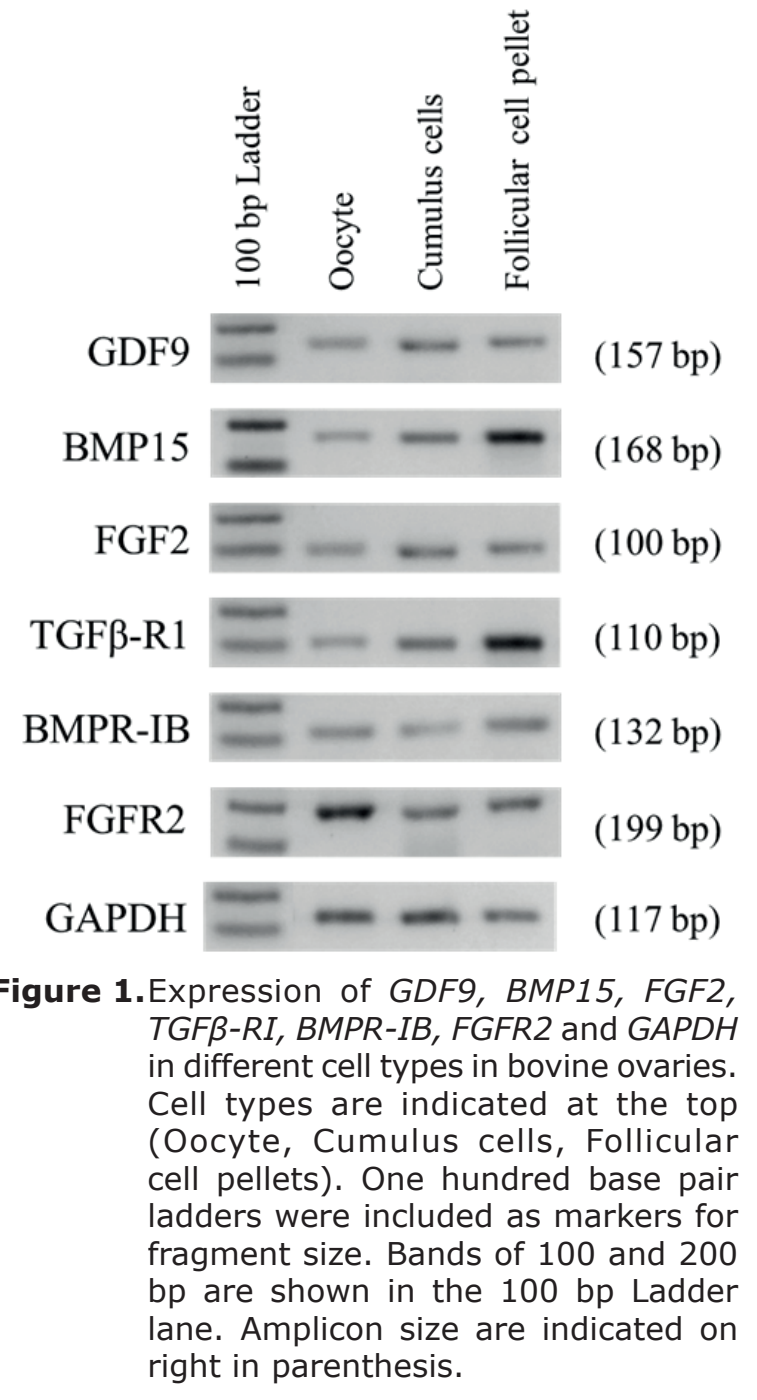

Al comparar roedores con un ciclo estral incompleto (ratones, ratas) con animales con un ciclo estral completo (humanos, cabras, cerdos y vacas), el GDF9 y el BMP15 aparecen en diferentes tejidos. La expresión de ARNm de los factores de crecimiento transformantes-beta estudiados se detectó exclusivamente en ovocitos de roedores (13), mientras que en otras especies, incluyendo humanos (14), cabras (15), ovejas $(8,16)$, cerdos (17) y vacas (BMP15 y GDF9) se expresaron en células de cúmulo así como en ovocitos, de acuerdo con el resultado obtenido en este trabajo. Además, en el presente estudio, el BMP15 y el GDF9 también se expresaron en el gránulo de células, donde se expresaron las células de la granulosa y la teca. Estos resultados podrían explicarse por las diferencias específicas de cada especie en los mecanismos de acción de las funciones biológicas clave entre las diferentes células foliculares. De acuerdo con otros autores, estas diferencias podrían 
these species-specific functional differences between mono- and poly-ovulatory animals were attributed to the distinct timing of the transformation of the BMP15 pro-protein into a functionally mature BMP15 (18).

GDF9 and BMP15 growth factors bind to specific receptors to trigger its mechanisms of action on the target cell. TGF $\beta-R 1$ mRNA expression was detected in granulosa cells of sheep and cows $(19,22)$. BMPR-IB mRNA expression has been observed in goat, sheep, pig and bovine follicles $(8,23,24)$, nevertheless here we report for the first time that $T G F \beta-R 1$ and $B M P R-I B$ MRNA are expressed in bovine oocytes.

Fibroblast growth factors (FGFs) are implicated in pregnancy success by regulating embryogenesis, implantation, and placentation through cell survival, migration, and differentiation (25). $F G F 2$, also known as basic FGF, has distinct roles during early embryogenesis in ruminants (26). FGF2 and its receptor FGFR2 are expressed during development of bovine embryos and a combination of FGF2 and transforming growth factor beta (TGF $\beta$ ) improves the development of the bovine embryo (27). The FGF2 mRNA expression was detected in oocytes, cumulus granulosa cells, mural granulosa and theca cells strengthening the systemic role during folliculogenesis $(7,8)$. It has been proposed that, oocyte-derived FGF2 could promote the primordial to primary follicle transition by signaling granulosa and stromal cells (28). In agreement, Khatib et al (29) suggest that FGF2 plays a positive role in the endogenous production of estrogens in humans (29). Furthermore, the angiogenic capacity of FGF2 described in follicles, generates proliferation of capillaries that follow the selection of the pre ovulatory follicle, resulting in a greater supply of nutrients and precursors, enhancing the growth of the dominant follicle (30). In previous work, it was suggested that FGF2 promotes mitosis of granulosa cells, theca, and ovarian stroma. It also enhances follicle survival, growth and formation of the antro during long term in vitro cultures of buffalo preovulatory follicles and improves steroidogenesis $(30,31)$.

Although the biological significance of the expression of these factors in follicular somatic cells has not been fully elucidated, previous reports and the results of the present study indicate the possibility that these factors in somatic cells as well as in oocytes may regulate the selection of follicle and/or ovulation in species with a complete estrous cycle. The presence of GDF9, BMP15, FGF2, TGF $\beta-R 1, B M P R-I B$ and FGFR2 transcripts in the studied cells indicate explicarse por las diferencias en las formas fisiológicas y reproductivas de las especies estudiadas, sugiriendo que estos factores regulan la tasa de ovulación y la fertilidad femenina de forma específica para cada especie $(20,21)$. Recientemente, estas diferencias funcionales específicas para cada especie entre animales mono y poliovulatorios se atribuyeron al distinto momento de la transformación de la proteína BMP15 en un BMP15 funcionalmente maduro (18).

Los factores de crecimiento GDF9 y BMP15 se unen a receptores específicos para activar sus mecanismos de acción en la célula diana. Se detectó expresión de ARNm TGF $\beta-R 1$ en células granulosas de ovejas y vacas $(19,22)$. ARNm $B M P R-I B$ se detecto en folículos caprinos, ovinos, porcinos y bovinos $(8,23,24)$ sin embargo aquí reportamos por primera vez que ARNm de TGFB-R1 y BMPR-IB se expresaron en ovocitos bovinos.

Los factores de crecimiento de los fibroblastos (FGFs) están implicados en el éxito del embarazo al regular la embriogénesis, la implantación y la placentación a través de la supervivencia, la migración y la diferenciación celular (25). FGF2, también conocido como FGF básico, tiene funciones distintas durante la embriogénesis temprana en rumiantes (26). El FGF2 y su receptor FGFR2 se expresan durante el desarrollo de embriones bovinos y una combinación de FGF2 y el factor de crecimiento transformante beta (TGFB) mejora el desarrollo del embrión bovino (27). La expresión de ARNm del FGF2 se detectó en ovocitos, cúmulos granulares, células murales granulosas y células teca fortaleciendo el papel sistémico durante la foliculogénesis $(7,8)$. Se ha propuesto que el FGF2 derivado de los ovocitos podría promover la transición de los folículos primordiales a primarios mediante la señalización de la granulosa y las células del estroma (28). De acuerdo, Khatib et al (29) sugieren que el FGF2 juega un papel positivo en la producción endógena de estrógenos en humanos (29). Además, la capacidad angiogénica del FGF2 descrita en los folículos, genera proliferación de capilares que siguen la selección del folículo preovulatorio, resultando en un mayor aporte de nutrientes y precursores, potenciando el crecimiento del folículo dominante (30). En trabajos anteriores, se sugirió que el FGF2 promueve la mitosis de las células granulosas, la teca y el estroma ovárico. También mejora la supervivencia del folículo, el crecimiento y la formación del antro durante cultivos in vitro a largo plazo de folículos preovulatorios de búfalo y mejora la esteroidogénesis $(30,31)$

Aunque la importancia biológica de la expresión de estos factores en las células somáticas foliculares no se ha dilucidado del todo, los informes anteriores y los resultados del presente 
that these factors could act as paracrine and autocrine regulators in folliculogenesis.

Our results show the presence of a complex intrafollicular regulatory system, consisting of GDF9, BMP15, FGF2 and their main receptors in bovine ovaries, in a good agreement with previous studies on different species and follicular cells. Our results show an intra-follicular granulosa cell mRNA expression of the above genes from bovine ovarian follicles. These findings support the concept that early stages of ovarian follicular growth and development are regulated by intra-ovarian factors. Furthermore, our data showed that the initial concept that GDF9, BMP15 and FGF2 are exclusively produced by the oocyte cannot be maintained for the bovine species. To move forward with these findings, the quantitative levels of differential expression dynamics of GDF9, BMP15, FGF2, TGF $\beta-R 1, B M P R-I B$ and FGFR2 in oocyte genes from bovine ovaries need further research.

\section{Acknowledgment}

This work was supported by the Federal Council of Science and Technology (COFECYT) [PFIPESPRO Linked No. 032/13. 2013/2015], Ministry of Science, Technology and Productive Innovation (MINCYT); National Agency for Scientific and Technological Promotion [PICT 1784-2013] and National Institute of Agricultural Technology [PNSA 1115053 and PRO 1231205]. estudio indican la posibilidad de que estos factores, tanto en las células somáticas como en los ovocitos, puedan regular la selección del folículo y/o la ovulación en especies con un ciclo estral completo. La presencia de transcripciones de GDF9, BMP15, FGF2, TGFB-R1, BMPR-IB y $F G F R 2$ en las células estudiadas indica que estos factores podrían actuar como reguladores paracrinos y autocrinos en la foliculogénesis.

Nuestros resultados muestran la presencia de un complejo sistema de regulación intrafolicular, compuesto por GDF9, BMP15, FGF2 y sus principales receptores en ovarios bovinos, en concordancia con estudios previos sobre diferentes especies y células foliculares. Nuestros resultados muestran una expresión de ARNm intrafolicular de células de granulosa de los genes anteriores de folículos ováricos bovinos. Estos hallazgos apoyan el concepto de que las primeras etapas del crecimiento y desarrollo folicular ovárico están reguladas por factores intraováricos. Además, nuestros datos mostraron que el concepto inicial de que el GDF9, el BMP15 y el FGF2 son producidos exclusivamente por el ovocito no puede mantenerse para la especie bovina. Para avanzar con estos hallazgos, los niveles cuantitativos de la dinámica de expresión diferencial de GDF9, BMP15, FGF2, TGFB-R1, $B M P R-I B$ y FGFR2 en genes de ovocitos de ovarios bovinos necesitan más investigación.

\section{Agradecimientos}

Este trabajo fue apoyado por el Consejo Federal de Ciencia y Tecnología (COFECyT) [PFIP-ESPRO Vinculado $N^{\circ}$ 032/13. 2013/2015], Ministerio de Ciencia, Tecnología e Innovación Productiva (MINCyT); Agencia Nacional de Promoción Científica y Tecnológica [PICT 1784-2013] e Instituto Nacional de Tecnología Agropecuaria [PNSA 1115053 y PRO 1231205].

\section{REFERENCES}

1. Sirard MA, Richard F, Blondin P, Robert C. Contribution of the oocyte to embryo quality. Theriogenology 2006; 65(1):126-136.

2. Paulini F, Silva RC, de Paula Rôlo JLJ, Lucci CM. Ultrastructural changes in oocytes during folliculogenesis in domestic mammals. J Ovarian Res 2014; 7(1):102.
3. Otsuka F, McTavish K, Shimasaki S. Integral Role of GDF-9 and BMP-15 in Ovarian Function. Mol Reprod Dev 2011; 78(1):921.

4. Chang H-M, Qiao J, Leung PCK. Oocytesomatic cell interactions in the human ovary-novel role of bone morphogenetic proteins and growth differentiation factors. Hum Reprod Update 2016; 23(1):1-18. 
5. Mishra SR, Thakur N, Somal A, Parmar MS, Reshma R, Rajesh G, et al. Expression and localization of fibroblast growth factor (FGF) family in buffalo ovarian follicle during different stages of development and modulatory role of FGF2 on steroidogenesis and survival of cultured buffalo granulosa cells. Res Vet Sci 2016; 108:98-111.

6. Mahesh YU, Gibence HRW, Shivaji S, Rao BS. Effect of different cryo-devices on In vitro maturation and development of vitrified-warmed immature buffalo oocytes. Cryobiology 2017; 75:106-116.

7. Schams $D$, Steinberg $V$, Steffl M, Meyer HHD, Berisha B. Expression and possible role of fibroblast growth factor family members in porcine antral follicles during final maturation. Reproduction 2009; 138(1):141-149.

8. Silva JRV, van den Hurk R, Figueiredo JR. Ovarian follicle development In vitro and oocyte competence: advances and challenges for farm animals. Domest Anim Endocrinol 2016; 55:123-135.

9. European Union (EU). COUNCIL REGULATION (EC) No $1099 / 2009$ on the protection of animals at the time of killing. Brussels, Belgium; 2009. http://www.fao. org/faolex/results/details/en/?details=LEXFAOC090989

10. de Loos F, van Vliet C, van Maurik P, Kruip TAM. Morphology of immature bovine oocytes. Gamete Res 1989; 24(2):197-204.

11. Hatzirodos N, Hummitzsch K, Irving-Rodgers HF, Rodgers RJ. Transcriptome comparisons identify new cell markers for theca interna and granulosa cells from small and large antral ovarian follicles. PLoS One 2015; 10(3):1-13.

12. Kaivo-Oja N, Bondestam J, Kämäräinen M, Koskimies J, Vitt U, Cranfield M, et al. Growth differentiation factor-9 induces Smad2 activation and inhibin B production in cultured human granulosa-luteal cells. J Clin Endocrinol Metab 2003; 88(2):755762.

13. Mester B, Ritter LJ, Pitman JL, Bibby $A H$, Gilchrist RB, McNatty KP, et al. Oocyte expression, secretion and somatic cell interaction of mouse bone morphogenetic protein 15 during the peri-ovulatory period. Reprod Fertil Dev 2015; 27(5):801-811.
14. Li Y, Li R-Q, Ou S-B, Zhang N-F, Ren L, Wei $\mathrm{L}-\mathrm{N}$, et al. Increased GDF9 and BMP15 mRNA levels in cumulus granulosa cells correlate with oocyte maturation, fertilization, and embryo quality in humans. Reprod Biol Endocrinol 2014; 12(1):81.

15. Pan ZY, Di R, Tang QQ, Jin HH, Chu MX, Huang $D W$, et al. Tissue-specific mRNA expression profles of GDF9, BMP15, and BMPR1B genes in prolific and non-prolific goat breeds. Czech J Anim Sci 2015; 60(10):452-458.

16. Kona SSR, Praveen Chakravarthi V, Siva Kumar AVN, Srividya D, Padmaja K, Rao $\mathrm{VH}$. Quantitative expression patterns of GDF9 and BMP15 genes in sheep ovarian follicles grown in vitro or cultured in vitro. Theriogenology 2016; 85(2):315-322.

17. Paradis F, Novak S, Murdoch GK, Dyck MK, Dixon WT, Foxcroft GR. Temporal regulation of BMP2, BMP6, BMP15, GDF9, BMPR1A, BMPR1B, BMPR2 and TGF $\beta-R 1$ mRNA expression in the oocyte, granulosa and theca cells of developing preovulatory follicles in the pig. Reproduction 2009; 138(1):115-129.

18. Hosoe M, Kaneyama K, Ushizawa K, Hayashi K, Takahashi T. Quantitative analysis of bone morphogenetic protein 15 (BMP15) and growth differentiation factor 9 (GDF9) gene expression in calf and adult bovine ovaries. Reprod Biol Endocrinol 2011; 9(1):33.

19. Haas CS, Rovani MT, Oliveira FC, Vieira $A D$, Bordignon V, Gonçalves PBD, et al. Expression of growth and differentiation Factor 9 and cognate receptors during final follicular growth in cattle. Anim Reprod 2016; 13(4):756-761.

20. Al-musawi $S L$, Walton $K L$, Heath $D$, Simpson CM, Harrison CA. Species differences in the expression and activity of bone morphogenetic protein 15. Endocrinology 2013; 154(2):888-899.

21. Chen $H$, Liu $C$, Jiang $H$, Gao $Y$, Xu M, Wang $\mathrm{J}$, et al. Regulatory Role of miRNA-375 in Expression of BMP15/GDF9 Receptors and its Effect on Proliferation and Apoptosis of Bovine Cumulus Cells. Cell Physiol Biochem 2017; 41(2):439-450. 
22. Juengel $J L$, Bibby $A H$, Reader $K L$, Lun $S$, Quirke LD, Haydon LJ, et al. The role of transforming growth factor-beta (TGF $\beta$ ) during ovarian follicular development in sheep. Reprod Biol Endocrinol 2004; 2:78.

23. Zoheir KMA, Harisa GI, Allam AA, Yang $L$, Li $X$, Liang $A$, et al. Effect of alpha lipoic acid on in vitro development of bovine secondary preantral follicles. Theriogenology 2017; 88:124-130.

24. Zhu, G., Guo, B., Pan, D., Mu, Y., \& Feng, S. Expression of bone morphogenetic proteins and receptors in porcine cumulus-oocyte complexes during in vitro maturation. Animal Reproduction Science, 2008; 104(24), 275-283.

25. Dorey K, Amaya E. FGF signalling: diverse roles during early vertebrate embryogenesis. Development 2010; 137(22):3731-3742.

26. Ozawa M, Yang QE, Ealy AD. The expression of fibroblast growth factor receptors during early bovine conceptus development and pharmacological analysis of their actions on trophoblast growth in vitro. Reproduction 2013; 145(2):191-201.

27. Zhang K, Hansen PJ, Ealy AD. Fibroblast growth factor 10 enhances bovine oocyte maturation and developmental competence in vitro. Reproduction. 2010; 140(6):815826.
28. Nilsson E, Parrott J a, Skinner MK. Basic fibroblast growth factor induces primordial follicle development and initiates folliculogenesis. Mol Cell Endocrinol. 2001; 175(1-2): 123-130.

29. Khatib H, Maltecca C, Monson RL, Schutzkus V, Wang X, Rutledge JJ. The fibroblast growth factor 2 gene is associated with embryonic mortality in cattle. J Anim Sci. 2008; 86(9):2063-2067.

30. Berisha B, Sinowatz F, Schams D. Expression and Localization of Fibroblast Growth Factor (FGF) Family Members during the Final Growth of Bovine Ovarian Follicles. Mol Reprod Dev. 2004; 67(2):162-171.

31. Rodríguez-Alvarez L, Sharbatib J, Sharbatib S, Coxa JF, Einspanier R, Ovidio Castro $F$. Differential gene expression in bovine elongated (Day 17) embryos produced by somatic cell nucleus transfer and in vitro fertilization. Theriogenology. 2010; 74(1):45-59. 